\title{
SUPERVISÃO PEDAGÓGICA E CRESCIMENTO PROFISSIONAL NO PROCESSO DE AVALIAÇÃO DE DESEMPENHO DOCENTE
}

\author{
Paula Arnaud Dias ${ }^{1}$ \\ Célia Ribeiro ${ }^{2}$
}

Resumo: A supervisão pedagógica é considerada, por muitos autores e legisladores, como uma mais-valia e um contributo imprescindivel para o crescimento e (re)qualificação das organizações escolares, bem como para a melhoria contínua do serviço educativo que prestam.

Assim, deverá ser encarada como uma ferramenta pedagógica ao serviço dos professores, ao longo de toda a sua carreira (formação contínua), bem como da organização escolar, promovendo, no seu interior, uma abordagem reflexiva e dialogante entre todos os atores educativos: escola aprendente.

Os dados apresentados evidenciam que a supervisão deve ser concebida como um instrumento de formação ao longo da vida, que potencializa a inovação, a autonomia e o crescimento profissional dos professores, consubstanciada numa aprendizagem que, apesar de possuir uma vertente individual (autorreflexão, autoavaliação, autoformação,...), deverá focalizar-se num contexto coletivo de partilha de saberes, de experiências, de vivências, caminhando, desta forma, para a promoção de uma escola reflexiva e detentora de professores igualmente reflexivos.

A Avaliação de Desempenho Docente (ADD) deve ser concebida como mais um processo de aprendizagem, de melhoria e de crescimento profissional, onde a supervisão surge como uma ferramenta ao serviço dessa melhoria e crescimento profissional.

Palavras-chave: organização aprendente; escola reflexiva; supervisão pedagógica; formação; melhoria; avaliação; desenvolvimento profissional.

\footnotetext{
${ }^{1}$ paula.arnaud@hotmail.com; Mestre em Ciências da Educação pelo Departamento de Economia, Gestão e Ciências Sociais - Centro Regional das Beiras da Universidade Católica Portuguesa, tendo sido orientada pelo segundo autor.

2 cribeiro@crb.ucp.pt; Professora Auxiliar do Centro Regional das Beiras da Universidade Católica Portuguesa.
} 


\title{
Title: $\quad$ PEDAGOGICAL SUPERVISION AND PROFESSIONAL GROWTH IN THE PROCESS OF TEACHER PERFORMANCE EVALUATION
}

\begin{abstract}
Educational supervision is considered by many authors and lawmakers, as an asset and an essential contribution to the growth and (re)qualification of school organizations, as well as to the continuous improvement of the educational service it provides.

Therefore, it should be understood as an educational tool at the service of teachers throughout their career (lifelong training), along with the school organization, promoting within a reflective thinking and a dialoguing approach, among all educational stakeholders towards a learning school.

By performing their purposes, they should apply the standard(s), the setting(s) and the supervision style(s) they realize as filling the needs and uniqueness of each teacher/school organization, always within an environment of action-thought that upholds learning and the improvement of the educational action of all the interlocutors.

Every supervising action (including teachers' performance assessment $(A D D)$ should be applied within processes where supervision and appraisal go "side by side", making synergies and complement, in favour of development and improvement of the educational service that the organization provides (to the students and to all of its professionals).

The presented data proves that supervision should be designed as an instrument of lifelong training, that enhances innovation, teachers autonomy and professional growth, based on learning that, despite having an individual side (self-thinking, self-assessment, self-training ...), should be focused in a context of collective sharing of know-hows, of practices, of life-experiences, thus evolving the promotion of a thinking school which holds equally thinking teachers.

Teacher's assessment must also be considered as another learning, improvement and professional growth process, where educational monitoring appears as a tool in service of that same improvement and professional growth.
\end{abstract}

Keywords: learning organisation; thinking school; educational supervision; training; improvement; assessment; professional development.

\section{INTRODUÇÃO}

A escola hoje, tal como a conhecemos, é um local onde se cruzam jovens com percursos de vida diversificados, com interesses, expectativas e vivências distintas e, muitas vezes, divergentes das da organização educativa e da sua função de ensinar, de educar e de formar para a vida ativa. 
Neste cenário educativo, surgem os professores com a árdua função de ensinar (formação intelectual) e de educar (formação para os valores e cidadania).

Assim, os professores deverão ser profissionais detentores de uma sólida formação científica, corresponsabilizados com a sua formação, atualização e aprendizagem ao longo da sua vida, reflexivos, autónomos e detentores de um espírito colaborativo e aberto à mudança e à inovação profissional.

Todo este processo de melhoria e crescimento humano e profissional deverá ser acompanhado de uma supervisão pedagógica, iniciada aquando da formação inicial (professor estagiário) e acompanhar o professor ao longo de todo o seu percurso profissional (formação ao longo da vida).

Considera-se que todos os processos supervisivos deverão ser implementados num clima de partilha, de diálogo e de aprendizagem para todos os seus intervenientes. Só assim estaremos a desenvolver processos supervisivos com significância e com contributo formativo para a melhoria, a mudança e o crescimento dos seus atores educativos (supervisão pedagógica) e organização educativa (supervisão escolar).

Todos os processos supervisivos devem ser avaliados, pelo que a supervisão e a avaliação devem ser parceiros indissociáveis e complementares em todas as ações supervisivas, sejam elas de avaliação das aprendizagens, de avaliação das organizações educativas,...ou, mais recentemente, de ADD.

A ADD tem suscitado vários debates e opiniões divergentes, não pela sua pertinência e validade pedagógica, mas sim, pelo "mal-estar" criado no seio da classe docente, dada a forma como tem sido implementada.

O grande desafio que nos afigura hoje, e num futuro próximo, é criar "sinergias" entre avaliação-supervisão, e implementá-las segundo processos justos, válidos, criteriosos, dialógicos e que contribuam, verdadeiramente, para a aprendizagem, a reflexão e a qualidade do serviço educativo prestado pela escola, que se quer aprendente e qualificante (dos seus profissionais e alunos).

\section{SUPERVISÃO PEDAGÓGICA}

A supervisão em Portugal durante muitos anos foi pensada, sobretudo, por referência ao professor em formação inicial e à sua interação pedagógica em contexto de sala de aula.

A escola atual "exige" que lhe seja atribuída uma dimensão mais abrangente e se pense a supervisão como uma ferramenta significativa de apoio, de reflexão e de acompanhamento dos professores, ou seja, ensinar os professores a ensinar deve ser o objetivo principal de toda a supervisão 
pedagógica que se deve desenvolver ao longo de todo o percurso profissional, e que permita "o desenvolvimento da reflexividade profissional dos professores para a melhoria da qualidade das aprendizagens dos alunos" (Vieira \& Moreira, 2011, p.14).

Todas as situações de supervisão se devem caraterizar por relações interpessoais dinâmicas, encorajantes e facilitadoras da aprendizagem que conduzam a processos de desenvolvimento e de melhoria tanto a nível pessoal como da própria organização.

\subsection{Evolução do conceito}

A noção de supervisão, no âmbito da educação, tem uma herança histórica relacionada com as funções de inspeção e controlo (Duffy, 1998; Mclntyre \& Byrd, 1998, citados por Vieira \& Moreira, 2011), verificando-se que o conceito de supervisão, associado ao contexto de formação de professores, foi introduzido em Portugal por Alarcão, na década de 80 (Alarcão, 1982, citada por Vieira \& Moreira, 2011).

De acordo com Alarcão e Tavares (2010), o termo supervisão já era amplamente utilizado nos países anglo-saxónicos e começou a ser aplicado em Portugal como alternativa à designação de "orientação da prática pedagógica" (p.9). Os mesmos autores consideram que:

\footnotetext{
a prática pedagógica é um dos componentes fulcrais do processo de formação de professores; é um processo lento que, iniciado na chamada formação inicial, não deve terminar com a profissionalização, mas prolongar-se sem quebra de continuidade na tão falada e tão pouco considerada formação contínua (p.9).
}

Para estes autores, a supervisão surge como um processo sistemático de orientação da prática pedagógica onde um professor mais experiente e informado orienta outro docente ou candidato à docência no seu desenvolvimento humano e profissional. "Depreende-se desta noção que a supervisão tem lugar num tempo continuado, pois só assim se justifica a sua definição como processo" (Alarcão \& Tavares, 2010, p.16). Esta visão da supervisão como um processo, que requer continuidade, é, também, defendida por Alarcão (2001) ao referir que na escola atual a supervisão deverá ser alargada a toda a organização (dimensão coletiva), no sentido de promover a melhoria “(...) não só à sala de aula, mas a toda a escola, não só aos professores isoladamente, mas na dinâmica das suas interações entre si e com os outros e na responsabilidade do ensino que praticam" (p.18), ou seja, desencadear no interior da organização escolar processos de supervisão que promovam a sua melhoria, bem como, maximizem a qualidade do serviço educativo que presta. A mesma autora 
defende (desde a década de 80) que a supervisão não deverá ser desenvolvida apenas no âmbito da formação inicial de novos professores, mas ser um processo continuado de formação ao longo da vida. Nesse sentido, as escolas deverão constituir-se como escolas reflexivas, detentoras de um pensamento sistémico, que promova o seu desenvolvimento e a sua aprendizagem ao longo da sua história. Toda a escola reflexiva deve ser concebida como uma comunidade aprendente e, desenvolver-se, através do seu “(...) pensamento e prática reflexiva que acompanha o desejo de compreender a razão de ser da sua existência, as caraterísticas da sua identidade própria, os constrangimentos que a afetam e as potencialidades que detém" (Alarcão, 2001, p.17).

Oliveira-Formosinho (2002a) defende que a primeira década do século XXI corresponde ao tempo ideal para se proceder à qualificação da escola e dos seus profissionais, o que requer uma supervisão contextualizada e que dê resposta aos problemas vivenciados em cada contexto educativo, ou seja, é tempo para a "proposição de uma supervisão repensada no seu conceito, papel e funções" (p.12). Esta nova visão de supervisão, que se desenvolve e se reconstrói, terá de se colocar no papel de apoio (e não de inspeção), de escuta, de colaboração ativa, de envolvimento na ação educativa quotidiana, de experimentação refletida através da ação que tem como finalidade responder a um problema identificado, ou seja, é fundamental "pensar a supervisão como instrumento de formação, inovação e mudança, situando-a na escola como organização em processo de desenvolvimento e de (re)qualificação" (p.13).

Constatamos, tal como já foi referido anteriormente, que na atualidade a supervisão pedagógica já não está associada apenas à formação inicial de professores, mas também à formação ao longo da vida, a formação contínua, onde as atividades supervisiva e pedagógica deverão fazer parte de um mesmo projeto: indagar e melhorar a qualidade da ação educativa.

Decorre, desta ideia, o pressuposto básico de que a pedagogia sem supervisão será menos pedagógica, ou seja, qualquer professor, no exercício da sua profissão deverá regular criticamente a sua ação. Neste sentido, a supervisão surge como uma necessidade da ação profissional consciente e deliberada de cada professor, onde a auto-supervisão e a supervisão acompanhada contribuem de forma determinante para o seu crescimento e autonomia profissional (Vieira \& Moreira, 2011).

Esta ideia, de supervisão como processo de formação profissional e humano ao longo da vida, já era defendida por Alarcão e Tavares (1987), ao afirmarem que "no quadro de formação contínua, a supervisão da prática pedagógica emerge como uma auto e heteroavaliação, comprometida e colaborante, em que os professores se entre-ajudam a desenvolver-se e a melhorar o seu próprio ensino" (p.148). 
Destacamos, devido à sua abrangência, o conceito de supervisão segundo Oliveira-Formosinho (2002b), cujas linhas orientadoras se passam a apresentar no quadro I.

\section{Quadro I}

Caraterísticas da supervisão segundo Oliveira-Formosinho (2002)

- a supervisão é um processo de apoio à formação (inicial e/ou contínua);

- a formação deve ser concebida como aprendizagem profissional contínua que envolve as pessoas, os seus saberes, as suas funções e as suas realizações;

- o teor sistemático da formação deverá ser realizado num contexto de ação-reflexão das práticas dentro da sala de aula;

- os meios para desenvolver o processo supervisivo deverão contemplar a planificação, a observação, a reflexão, o diálogo, a comunicação, a avaliação, entre outros;

- a compreensão de que todo o processo supervisivo promove outros processos, nomeadamente o processo de aprendizagem e desenvolvimento dos alunos (os atuais e os futuros);

- a consciencialização, por parte dos professores, que todos os processos supervisivos implicam também, abertura aos contextos sociais envolventes (crenças, cultura e valores da sociedade).

Fonte: adaptado de Oliveira-Formosinho (2002b, p.116).

Assim, segundo esta autora, todo o processo de supervisão deverá ser concebido como apoio à formação, defendendo que toda a formação deverá ser planificada segundo uma conceção integradora de várias dimensões, entre elas o currículo, o processo de ensino-aprendizagem, a sala de aula, a escola no seu todo, mas também a sociedade envolvente, através dos seus valores, das suas crenças e da sua cultura. Toda esta articulação de saberes e vivências contextualizadas à organização escolar darão sentido, validade e rigor a todos os processos em torno do processo de ensino e de aprendizagem.

Concluindo, a supervisão é um processo complexo, que promove outros processos, numa lógica evolutiva e dinâmica que dá resposta às necessidades e aos desafios com que cada organização escolar é confrontada. "É, assim, naturalmente um processo complexo onde muito está previamente pensado, onde muito é emergente" (OliveiraFormosinho, 2002b, p.118).

Garmston, Lipton e Kaiser (2002) identificam três funções específicas da supervisão, a saber: o melhoramento da prática, o desenvolvimento do potencial individual para a aprendizagem e a promoção da capacidade de autorrenovação da organização, as quais são apresentadas no quadro II. 


\section{Quadro II}

Funções da supervisão

\begin{tabular}{|c|c|}
\hline Funções da supervisão & Princípios orientadores \\
\hline Melhoria da prática & $\begin{array}{l}\text { - Consideram que a melhoria da prática se pode } \\
\text { verificar ao nível: } \\
\text { - da instrução do professor no âmbito do seu estilo } \\
\text { pessoal de ensino (estilo cognitivo e crenças } \\
\text { pessoais a nível educacional); } \\
\text { - da prática global do professor (aumento da sua } \\
\text { eficácia junto dos alunos o que pode desencadear } \\
\text { uma renovação das suas práticas pedagógicas); } \\
\text { - da prática do ensino em geral (o professor } \\
\text { fortalecer, desenvolver e melhorar a sua prática de } \\
\text { ensino e de pedagogia no sentido de promover a } \\
\text { melhoria dos resultados dos alunos e da escola). }\end{array}$ \\
\hline $\begin{array}{l}\text { Desenvolver o potencial } \\
\text { individual para a } \\
\text { aprendizagem }\end{array}$ & $\begin{array}{l}\text { - Promover o questionamento e a reflexão por parte } \\
\text { do professor em todas as fases de ensino } \\
\text { (planificação, contexto de sala de aula e após o } \\
\text { ensino); } \\
\text { - Desencadear, no professor, processos de } \\
\text { crescimento profissional e de abertura à mudança; } \\
\text { - Potencializar a capacidade de diagnosticar e } \\
\text { resolver problemas no âmbito da prática } \\
\text { pedagógica. }\end{array}$ \\
\hline $\begin{array}{l}\text { Promover a capacidade de } \\
\text { auto-renovação da } \\
\text { organização }\end{array}$ & $\begin{array}{l}\text { - Desenvolver a organização no sentido da sua auto- } \\
\text { renovação e motivação dos seus agentes } \\
\text { educativos; } \\
\text { - Promover uma cultura de trabalho reflexivo e } \\
\text { orientado para o questionamento; } \\
\text { - Potencializar professores capazes de serem autores } \\
\text { de si próprios, responsáveis e empenhados numa } \\
\text { auto-renovação colaborativa que promova a } \\
\text { melhoria da escola e do serviço educativo que } \\
\text { prestam. }\end{array}$ \\
\hline
\end{tabular}

Fonte: adaptado de Garmston e colaboradores (2002, pp.24-26).

\subsection{Modelos de supervisão - conhecer para compreender}

No sentido de analisar e compreender melhor o conceito de supervisão torna-se necessário caraterizar, os vários modelos de supervisão, no tocante às suas potencialidades e às suas limitações.

De acordo com Tracy (2002), não existe um consenso relativamente à classificação de modelos no âmbito da supervisão do ensino. Os modelos deverão ser concebidos como estruturas que orientam a nossa investigação e prática de supervisão, criando profissionais em permanente crescimento e desenvolvimento pessoal, o que conduzirá também ao desenvolvimento da organização, "a supervisão deve criar o elo entre as necessidades individuais do professor e os objetivos escolares, uma 
função que não acontece por acaso" (Glickman, 1990, citado por Tracy, 2002, p.34).

No sentido de descrever as potencialidades e constrangimentos dos modelos de supervisão, Sergiovanni e Starratt (1993, citados por Tracy, 2002, pp.26-27) recorrem à metáfora das janelas e dos muros, verificando-se que os modelos servem como janelas quando evidenciam e articulam a relação entre a teoria e a prática e funcionam como muros nos casos em que limitam e condicionam a nossa visão a outras conceções e perceções da realidade que nos rodeia. Quando os modelos retratam simultaneamente o lado conceptual e o prático da supervisão permitem que:

$$
\begin{aligned}
& \text { (...) os profissionais e investigadores vejam mais } \\
& \text { claramente a ligação entre teoria e prática. A visão que os } \\
& \text { profissionais têm da janela inclui novos pormenores } \\
& \text { acerca do porquê da prática - ao aplicar este modelo, o } \\
& \text { que é que ele me diz acerca do que eu penso do ensino e } \\
& \text { da aprendizagem? O investigador vê a teoria da forma } \\
& \text { como ela poderá ser aplicada (...) quais são os requisitos } \\
& \text { para implementar eficazmente esta visão ideal (Tracy, } \\
& \text { 2002, p.27). }
\end{aligned}
$$

Tracy (2002) descreve/expõe seis trabalhos, onde estão presentes vários modelos de supervisão pedagógica. Todos estes modelos têm como objetivo clarificar e organizar o nosso próprio pensamento, bem como, permitir a formulação de perguntas e de reflexões que conduzam ao surgimento e/ou desenvolvimento de novos modelos supervisivos. Todo este estudo é apresentado no quadro III. 


\section{Quadro III}

Modelos de supervisão pedagógica

\begin{tabular}{|c|c|c|c|}
\hline Trabalhos & Modelos Supervisivos & Algun(s) autor(es) & $\begin{array}{l}\text { Caract. } \\
\text { organiz. }\end{array}$ \\
\hline \multirow{3}{*}{$\begin{array}{l}\text { ASCD } \\
(1982)\end{array}$} & Científico & McNeil & \multirow{3}{*}{$\begin{array}{l}\text { Derivação do } \\
\text { significado de } \\
\text { ensino }\end{array}$} \\
\hline & Clínico & $\begin{array}{l}\text { Garman, Cogan, } \\
\text { Goldhammer }\end{array}$ & \\
\hline & Artístico & Eisner & \\
\hline \multirow{4}{*}{$\begin{array}{l}\text { Glatthorn } \\
\text { (1984) }\end{array}$} & Supervisão clínica & $\begin{array}{c}\text { Cogan e } \\
\text { Goldhammer, Hunter, } \\
\text { McNeil, Eisner }\end{array}$ & \multirow{4}{*}{ Controle } \\
\hline & $\begin{array}{l}\text { Desenvolvimento } \\
\text { profissional cooperativo }\end{array}$ & Nenhum citado & \\
\hline & $\begin{array}{c}\text { Desenvolvimento } \\
\text { autodirecionado }\end{array}$ & Iwanicki e Redfern & \\
\hline & Monitorização administrativa & Nenhum citado & \\
\hline \multirow{5}{*}{$\begin{array}{l}\text { McGreal } \\
(1983)\end{array}$} & Normas comuns & Nenhum citado & \multirow{5}{*}{$\begin{array}{l}\text { Foco e } \\
\text { objetivo da } \\
\text { supervisão }\end{array}$} \\
\hline & Estabelecimento de objetivos & Iwanicki & \\
\hline & Produtos & Popham, McNeil & \\
\hline & Supervisão clínica & $\begin{array}{c}\text { Cogan, Goldhammer, } \\
\text { Acheson e Gall, } \\
\text { Boyan e Copeland }\end{array}$ & \\
\hline & Artístico ou naturalista & Eisner, Sergiovanni & \\
\hline \multirow{4}{*}{$\begin{array}{l}\text { Pajak } \\
(1993)\end{array}$} & Original & Goldhmmer, Cogan & \multirow{4}{*}{$\begin{array}{l}\text { Conceção da } \\
\text { prática } \\
\text { profissional }\end{array}$} \\
\hline & Humanístico-artístico & Blumberg, Eisner & \\
\hline & Técnico-didático & $\begin{array}{c}\text { Acheson e Gall, } \\
\text { Hunter } \\
\end{array}$ & \\
\hline & Desenvolvimental/reflexivo & $\begin{array}{l}\text { Glickman, Garman, } \\
\text { Schön }\end{array}$ & \\
\hline \multirow{5}{*}{$\begin{array}{l}\text { Sergiovanni } \\
\text { e Starratt } \\
(1993)\end{array}$} & Supervisão clínica & Goldhmmer e Cogan & \multirow{5}{*}{$\begin{array}{l}\text { Autoridade } \\
\text { profissional }\end{array}$} \\
\hline & Supervisão colegial & Nenhum citado & \\
\hline & Supervisão autodirecionada & Nenhum citado & \\
\hline & Supervisão informal & Nenhum citado & \\
\hline & $\begin{array}{c}\text { Supervisão baseada na } \\
\text { pesquisa }\end{array}$ & Nenhum citado & \\
\hline \multirow{3}{*}{$\begin{array}{c}\text { Tracy e } \\
\text { MacNaugthon } \\
\text { (1993) }\end{array}$} & $\begin{array}{l}\text { Orientado para meios } \\
\text { (Tradic/Neotradic) }\end{array}$ & $\begin{array}{c}\text { Nenhum } \\
\text { citado/Hunter e } \\
\text { Minton }\end{array}$ & \multirow{3}{*}{$\begin{array}{l}\text { Foco na } \\
\text { supervisão }\end{array}$} \\
\hline & $\begin{array}{l}\text { Orientado para objetivos } \\
\text { (Educac/Desemp) }\end{array}$ & $\begin{array}{l}\text { McNeil/Iwanicki e } \\
\text { Redfern }\end{array}$ & \\
\hline & Orientado para o professor & Goldhmmer e Cogan & \\
\hline
\end{tabular}

Fonte: adaptado de Tracy (2002, pp.39-68).

Abordando os vários modelos de supervisão, segundo Tracy (2002), surge-nos naturalmente, uma pergunta: que critérios e pressupostos devemos ter em mente/contemplar quando procedemos à seleção de um 
modelo supervisivo? O autor refere que "os modelos devem funcionar como janelas que iluminam a nossa investigação e prática da supervisão, então eles devem expandir o nosso pensamento em vez de o limitarem a padrões restritos" (p.73).

Pelo exposto, somos levados a considerar que não devemos ter uma visão redutora da supervisão e do ensino e, nesse sentido, teremos que analisar com muita propriedade e saber a natureza da organização e, posteriormente, selecionar um conjunto de modelos que de forma articulada deem resposta às necessidades e especificidades dessa organização educativa (os modelos completam-se pois valorizam aspetos diferentes da prática supervisiva).

Constatamos que a generalidade dos modelos apresentados se baseia, segundo Tracy (2002), nos seguintes objetivos:

\begin{abstract}
1. O professor é o protagonista no processo de transmissão do ensino; 2. O ensino é um acto observável; 3 . O acto de ensinar ocorre num tempo e lugar predestinados, nos quais o supervisor pode estar presente; 4. Os comportamentos de ensino do professor e as interacções com os alunos são acontecimentos significativos a observar no ambiente de aprendizagem; 5. A interacção professor-supervisor é um meio eficaz de identificação dos aperfeiçoamentos pedagógicos necessários; 6. A interacção professorsupervisor deveria ocorrer face a face (p.80).
\end{abstract}

Estamos conscientes que à medida que o sistema educacional se vai transformando, também os modelos supervisivos deverão acompanhar essa mudança e serem reformulados no sentido de darem resposta às novas necessidades e "vivências" nos contextos educativos. Tracy (2002) refere que os objetivos da supervisão no futuro "serão provavelmente alterados, passando da ênfase no ensino para a ênfase na aprendizagem" (p.82) e, nestas circunstâncias, todos os membros da organização se desenvolvem de forma continua e independentemente do papel que desempenham (formação de comunidades de aprendizagem). A supervisão no futuro deve centrar-se "na colaboração e no desempenho do grupo, ao mesmo tempo que fornece feedback suficientemente pormenorizado para se tornar útil ao aperfeiçoamento individual dentro do grupo" (Tracy, 2002, p.83).

Pelo exposto, a futura geração de modelos de supervisão deverá dar enfase às premissas apresentadas no quadro IV. 


\section{Quadro IV}

Pressupostos da futura geração de modelos supervisivos

- A escola é uma comunidade construída por elementos que são aprendizes ao longo de todo o ciclo de vida;

- As pessoas são capazes de assumir responsabilidades pelo seu desenvolvimento, de se autodirigirem e de se autosupervisionarem, quando têm acesso a recursos e mecanismos de acompanhamento adequados;

- Os aprendizes adultos têm as suas necessidades próprias, distintas das necessidades das crianças;

- Para melhorar o desempenho de qualquer indivíduo, devemos ter em consideração o ambiente organizacional global no qual essas pessoas trabalham;

- As pessoas aprendem melhor e são motivadas pela colaboração com outros.

Fonte: Tracy (2002, pp.83-84).

\subsection{Cenários de supervisão}

No sentido de analisar e compreender melhor as práticas de supervisão, apresentamos os nove cenários de supervisão de Alarcão e Tavares (2003), que não devem ser concebidos como "compartimentos estanques ou categorias" (p.17) mas, devem coexistir e complementaremse com a finalidade de darem resposta às necessidades e especificidades de cada contexto educativo.

São apresentados, de forma sucinta, os nove cenários supervisivos, segundo Alarcão e Tavares (2003):

- cenário da imitação artesanal, está subjacente a ideia de imitar os bons modelos, aqueles que tudo sabem, que são detentores da autoridade e do conhecimento: os mestres. Considerava-se que a melhor maneira do saber-fazer é através da imitação, ou seja, "o modelo do artífice medieval a ser moldado pelo artesão e a ser, através dele, socializado" (Alarcão \& Tavares, 2003, p.17). O professor executa de forma passiva e sem discussão o modelo transmitido pelo "seu mestre".

- cenário da aprendizagem pela descoberta guiada, centra-se na investigação e no estudo das variáveis que influenciam o processo de ensino e aprendizagem. Segundo este cenário, o professor é conhecedor dos vários modelos teóricos, deverá observar diferentes professores em contexto de sala de aula, e posteriormente pôr "em uso" as ferramentas teóricas e práticas que foi adquirindo/observando em várias experiências educativas (formação teórico-prática). O professor surge com um papel ativo e autocrítico, pondo em prática os conhecimentos que foi adquirindo sobre o ensino e a aprendizagem (parte de uma componente teórica e da observação para a componente prática). Este cenário põe em ênfase a capacidade de descoberta e de inovação pedagógica.

- cenário behaviorista, recorre à técnica do microensino, dos anos 60 , a qual defende que todos os professores executam determinadas 
tarefas que, numa fase posterior, devem ser apresentadas, explicadas, analisadas com os novos professores. De seguida, estes deverão pô-las em prática, numa aula específica para o efeito e, toda a sua atuação pedagógica é analisada pelos alunos, pelo supervisor e, por vezes, pelos colegas. $\mathrm{O}$ grande constrangimento deste cenário é que não antecipa situações reais, com as quais os futuros professores são confrontados na sua prática letiva diária.

- cenário clínico, neste cenário o futuro professor é parte integrante e dinâmica de todo o processo supervisivo, existindo um espírito de colaboração e de interajuda entre o supervisor e professor, em todas as etapas do processo, nomeadamente, a planificação, a observação e a análise de aulas e o próprio processo de avaliação. Este cenário tem implícito três elementos estruturantes, a saber: planificar, interagir e avaliar. Todos estes parâmetros estão presentes no processo de ensino, e concluem que "fazer supervisão é, no fundo, uma forma de ensinar" (p.28).

- cenário psicopedagógico, o ato supervisivo surge com a finalidade de ensinar a ensinar, através do desenvolvimento de capacidades/competências no futuro professor que lhe permitam resolver problemas e tomar decisões de forma fundamentada e pedagogicamente corretas. Entre o supervisor-professor cria-se uma relação de ensino/aprendizagem, num ambiente dialogante e encorajador.

- cenário pessoalista, neste cenário é dada relevância ao desenvolvimento da pessoa do professor, alicerçada no seu autoconhecimento, no seu autodesenvolvimento, tendo por base o diagnóstico das suas necessidades e das suas preocupações no tocante à qualidade e eficácia do ensino que ministra. Nesta perspectiva, a formação de professores deve incidir em experiências vivenciais, ajudando-os a refletir sobre as mesmas, bem como, a analisar o impacto que estas apresentam no seu crescimento pessoal (humanista) e profissional.

- cenário reflexivo, esta abordagem tem o seu enfoque na reflexão sobre a ação, ou seja, defende uma reflexão dialogante sobre o que foi observado e vivido. O papel do supervisor será ajudar os futuros professores a compreenderem as situações, a saberem agir em situação, a sistematizarem o conhecimento, no sentido de promover o crescimento/aprendizagem profissional do professor de forma ativa, reflexiva e emancipatória.

- cenário ecológico, neste cenário é colocado o enfoque nas dinâmicas sociais. Nesta conceção de desenvolvimento pessoal e profissional do professor, a supervisão surge com a função de "proporcionar e gerir experiências diversificadas", em contextos 
diversificados e, permitir, a ocorrência de "transmissões ecológicas", as quais possibilitam ao futuro professor o desempenho de novas atividades/papéis e a "interacção com pessoas até aí desconhecidas" (p.37). Este processo valoriza a aprendizagem/formação ao longo do tempo (formação contínua), a coaprendizagem institucional, a reflexão para, na e sobre a ação.

- cenário dialógico, este cenário valoriza a dimensão emancipatória da formação, reconhecendo que é através do diálogo que se constrói a cultura e o conhecimento profissional dos professores, defendendo portanto, uma supervisão colaborativa e dialógica em detrimento da individualizada. Preconiza-se, por último, uma supervisão alicerçada em "relações simétricas de colaboração e de base clínica" a qual funcione também como "instrumento de emancipação individual e coletiva de professores" (Alarcão \& Tavares, 2003, p.41).

Por último, Alarcão e Tavares (2003) registam três ideias estruturantes, que deverão ser contempladas na supervisão pedagógica de professores, que se passam a registar, no quadro V.

\section{Quadro V}

Pressupostos que devem presidir à supervisão de professores

- O professor é uma pessoa, um adulto, um ser ainda em desenvolvimento, com um futuro de possibilidades e um passado de experiências;

- O professor, ao aprender a ensinar, encontra-se ele próprio numa situação de aprendizagem;

- O supervisor é também uma pessoa, também ele um adulto em desenvolvimento, geralmente com mais experiência; a sua missão consiste em ajudar o professor a aprender e a desenvolver-se para, através dele, influenciar a aprendizagem e o desenvolvimento dos alunos.

Fonte: Alarcão e Tavares (2003, p.42).

\subsection{Estilos de supervisão}

O supervisor é alguém que se preocupa em ajudar os futuros professores a crescerem de forma sustentada e a desenvolverem a sua autonomia profissional. Todo o processo supervisivo surge com a finalidade de apoiar e regular o processo formativo dos formandos, contribuindo para o alargamento da sua visão sobre o ensino, estimulando e potencializando o seu autoconhecimento e a sua reflexão sobre as práticas educativas que implementam diariamente (Alarcão \& Roldão, 2010).

A grande maioria dos investigadores refere que o supervisor deve ser um profissional com grande capacidade de prestar atenção, compreender e saber escutar, mas também deverá "manifestar uma atitude de resposta adequada, de integrar as perspetivas dos formandos, de buscar 
clarificação de sentidos e a construção de uma linguagem comum, de comunicar verbal e não-verbalmente, de parafrasear e interpretar, de cooperar, de interrogar" (Alarcão \& Tavares, 2003, p.74). Pelo exposto, a ação supervisiva deve ser alicerçada em competências interpessoais ou skills interpessoais, que segundo Glickman (1985), citado por Alarcão e Tavares (2003, pp.74-75), surgem agrupados em dez categorias, a saber: 1) prestar atenção ao que os formandos dizem e fazem; 2) clarificar o que se ouve e o que se diz; 3) encorajar emitindo ou não reforços positivos; 4) servir de espelho devolvendo e tornando visível para o emissor o sentido das frases; 5) dar opinião; 6) ajudar a encontrar soluções para os problemas; 7) negociar opções indicando ou não hipóteses de possíveis resultados; 8) orientar; 9) estabelecer critérios; 10) condicionar. Este autor defende que a ênfase dada pelo supervisor a alguns destes skills interpessoais irá condicionar o seu estilo de supervisão, que recairá sobre uma das seguintes categorias/estilos supervisivos: não-diretiva, de colaboração ou diretivo, que se passam a apresentar (p.75):

- não-diretivo, considera que o supervisor é capaz de entender o mundo do professor, de o escutar, de o encorajar, de o ajudar na clarificação de ideias e na resolução de problemas. O supervisor permite que o futuro professor tome as iniciativas, exponha e explique as suas ideias, ajudando-o e orientando-o na procura de um saber profissional cada vez mais completo e promotor de uma melhor educação para os alunos.

- de colaboração, o supervisor recorre a estratégias de colaboração, dando a sua opinião sobre o trabalho desenvolvido/observado pelo futuro professor. Nesse sentido, elabora sínteses das sugestões e dos problemas apresentados, e ajuda-o a resolvêlos num ambiente colaborativo, dialogante e reflexivo.

- diretivo, o supervisor condiciona as atitudes do futuro professor, prescreve o que fazer, fornecendo a sua visão das coisas e nesse sentido dá orientações e estabelece critérios rígidos que devem ser postos em uso pelo formando (condiciona as tarefas e a forma de as realizar).

Por último, considera-se que os estilos de supervisão não devem ser analisados e/ou utilizados de forma isolada e rígida, mas sim recorrer à sua articulação de acordo com as necessidades/especificidades de cada contexto supervisivo. Assim, os estilos supervisivos surgem num contínuo enquadramento, conforme evidencia o quadro VI. 


\section{Quadro VI}

Estilos de supervisão, segundo Glickman (1985)

\begin{tabular}{|c|c|c|c|c|}
\hline Comportamentos & $\begin{array}{l}\text { - Prestar } \\
\text { atenção } \\
\text { - Clarificar } \\
\text { - Encorajar }\end{array}$ & $\begin{array}{c}\text { - Servir de } \\
\text { espelho }\end{array}$ & $\begin{array}{l}\text { - Dar opinião } \\
\text { - Ajudar a } \\
\text { encontrar } \\
\text { soluções } \\
\text { - Negociar }\end{array}$ & $\begin{array}{l}\text { - Orientar } \\
\text { - Estabelecer } \\
\text { critérios } \\
\text { - Condicionar }\end{array}$ \\
\hline Não-diretivo & & & & \\
\hline \multicolumn{5}{|l|}{ De colaboração } \\
\hline Diretivo & & & & \\
\hline
\end{tabular}

Fonte: adaptado de Alarcão e Tavares (2003, p.76).

Para Severino (2007), citado por Gonçalves (2009, p.31), existem três estilos de supervisão, que se passam a descrever:

- estilo apoiante, valoriza a pessoa recorrendo a uma supervisão reativa, segundo a qual o supervisor aceita os pensamentos, ouve e analisa as ideias do professor, esperando que seja este a tomar as iniciativas. A cooperação, o apoio, a empatia, o encorajamento são algumas das caraterísticas que o supervisor coloca em ação em todo o processo supervisivo.

- estilo interpretativo, trata-se de uma supervisão ativa onde se valorizam mais as próprias ideias do supervisor do que os pontos de vista dos formandos. No entanto, o formando é acompanhado e questionado de forma sistemática acerca da sua prática e implementam-se processos que conduzam à mudança e ao seu crescimento profissional.

- estilo prescritivo, tem associada uma supervisão ativa, onde o supervisor se preocupa fundamentalmente com os comportamentos a desenvolver nos formandos, nomeadamente a competência técnica, a qual se traduz no aperfeiçoamento de técnicas de gestão e instrução, bem como, adquirirem os comportamentos mais apropriados na resolução de determinadas situações. Segundo este estilo supervisivo, o supervisor é visto como um mestre ou mentor, não abdicando de desenvolver, paralelamente, um processo de apoio e/ou de elucidar o seu formando sempre que julgue necessário.

\section{AVALIAÇÃO DE DOCENTES NO CONTEXTO DE SUPERVISÃO}

As organizações escolares necessitam de desenvolver no seu interior modelos de supervisão colaborativa que promovam uma cultura de trabalho reflexivo e dialogante. 
Segundo Cruz (2009), na supervisão colaborativa, ambos os sujeitos (avaliador e avaliado) são professores comprometidos com a autorreflexão das práticas de ensino e de aprendizagem reais e na implementação de experiências conducentes à resolução dos problemas diagnosticados.

O mesmo autor defende que a observação de aulas só desempenha uma função social e profissional se promover o aparecimento de novas ideias sobre o ensino, e se permitir desenvolver um ambiente de abertura, de confronto, de diálogo e de cumplicidade entre professores.

\subsection{Avaliação em educação}

Segundo a perspetiva histórica, o ato de avaliar está conotado com a noção de medição.

O conceito de avaliação, segundo Guba e Lincoln (1990, citados por Alaíz, Góis \& Gonçalves, 2003), foi sofrendo uma evolução, apresentando estes autores as "quatro gerações de avaliação" que se passam a descrever:

- Na "primeira geração" avaliar e medir são sinónimos. Deste modo, o avaliador é um técnico que deverá utilizar e aplicar uma bateria de testes ao indivíduo que é objeto de avaliação e atribuir-lhe uma classificação resultante desse desempenho;

- Na "segunda geração" o avaliador continua a ser perspetivado como um técnico, mas assume-se, fundamentalmente, como um especialista na definição de objetivos, centrados mais no processo, identificando os pontos fortes e fracos do avaliado relativamente aos objetivos previamente delineados;

- $\mathrm{Na}$ "terceira geração" o avaliador é um especialista, que descreve e aplica ou constrói instrumentos de avaliação. $\mathrm{O}$ avaliador desempenha o papel de juiz, emitindo para tal um juízo acerca do valor ou mérito do ato avaliado;

- Na "quarta geração" o avaliador negoceia com os stakeholders. É uma metodologia construtivista que envolve uma dialética contínua de interação, de análise crítica e de reanálise, em que os avaliados são (co)autores da sua avaliação. A avaliação é considerada como útil e promotora de melhoria.

Segundo Guerra (2003), todo o processo avaliativo em educação deve ser desencadeado com grande rigor, qualidade e responsabilidade no sentido de ele próprio ser um veículo de promoção da melhoria e mudança dentro da organização escolar. "A avaliação em educação deve contribuir para a melhoria da própria avaliação, ou seja, a avaliação não 
pode preocupar-se apenas com o valor educativo da prática, devendo ser, ela mesma, educativa" (p.22).

O mesmo autor refere que, hoje em dia, é aceite por todos a necessidade de se proceder a uma avaliação institucional das escolas e dos seus profissionais que permita melhorar as suas práticas. A avaliação deverá ser um processo de aprendizagem para todos aqueles que a realizam e para aqueles que dela se aproveitam, no sentido de se poderem tomar decisões que transformem a dinâmica da escola e das suas práticas pedagógicas.

Assim, é fundamental que todos os agentes educativos acreditem e legitimem a qualidade, o rigor e o uso da avaliação no campo educacional e que esta "faça sentido" para todos os grupos que constituem a organização escolar.

Atualmente, o grande desafio que se coloca à escola prende-se com a ADD. Segundo Baptista (2013), a ADD tem estado, nos últimos anos, na ribalta da discussão nem sempre pelas melhores razões, considerando que foram as políticas educativas que a colocaram na (des) ordem do dia.

\begin{abstract}
A avaliação faz parte de qualquer programa de formação ou desenvolvimento, enquanto estratégia de análise, reflexão e melhoria. O problema está no facto de se eleger e privilegiar a avaliação como instrumento do controlo remoto do sistema educativo e seus atores, reduzindo a importância da supervisão pedagógica, formativa e reflexiva, como forma de garantir a qualidade do serviço educativo (p.263).
\end{abstract}

Defendemos que os professores terão que se rever no processo avaliativo desencadeado e, sentirem que o mesmo é um processo contínuo, sistemático, supervisionado e que contribui para melhorar as práticas e provocar a melhoria.

Assim, a ADD deverá ter como função privilegiada o desenvolvimento profissional dos professores e pautar-se por objetivos essencialmente formativos, pelo que a prática de supervisão poderá e deverá ser um forte contributo e mais-valia para se atingir estes objetivos, facilitando, apoiando, acompanhando, sustentando, (re)conceptualizando o desenvolvimento profissional dos seus interlocutores.

No entanto, e como afirma Marchão (2011), se a função formativa for "subalternizada por uma função apenas classificativa pode determinar uma visão não de apoio, própria dos processos de supervisão, mas hierárquica e autoritária, apenas de avaliação/inspeção em que as relações interpessoais na escola podem acabar por ser afetadas" (p.2). A avaliação, segundo Pacheco e Flores (1999, citados por Marchão, 2011), deve servir "quer para as tomadas de decisão relativas à progressão na carreira, 
funcionando como elemento de discriminação do desempenho, quer para o reforço do desenvolvimento profissional" (p.2).

No sentido de compreender melhor os campos de atuação da supervisão e da avaliação, num processo de supervisão-avaliação, apresentamos no quadro VII, alguns critérios de distinção.

\begin{tabular}{|c|c|c|}
\hline \multicolumn{3}{|c|}{$\begin{array}{c}\text { Quadro VII } \\
\text { Supervisão de avaliação: o que os distingue }\end{array}$} \\
\hline & Supervisão & Avaliação \\
\hline $\begin{array}{l}\text { Finalidade } \\
\text { principal }\end{array}$ & $\begin{array}{l}\text { Proporcionar o crescimento } \\
\text { do professor para além do } \\
\text { atual nível de desempenho. }\end{array}$ & $\begin{array}{lrr}\text { Formular juízo de } & \text { valor } \\
\text { acerca da qualidade } & \text { global } \\
\text { de competências } & \text { do } \\
\text { professor. } & & \\
& & \end{array}$ \\
\hline Fundar & $\begin{array}{l}\text { Reconhecer a natureza } \\
\text { complexa e multidimensional } \\
\text { do ato de ensinar. }\end{array}$ & $\begin{array}{l}\text { Direito legítimo do estado de } \\
\text { proteger as crianças e os } \\
\text { jovens do comportamento } \\
\text { imoral, da incompetência ou } \\
\text { pouca profissionalidade dos } \\
\text { professores. }\end{array}$ \\
\hline Âmbito & to. & Alargado. \\
\hline $\begin{array}{l}\text { Enfoque da } \\
\text { recolha de dados }\end{array}$ & $\begin{array}{l}\text { Individualizado, } \\
\text { diferenciado, baseado em } \\
\text { critérios individuais. }\end{array}$ & $\begin{array}{l}\text { Baseado em } \\
\text { estandardizados. }\end{array}$ \\
\hline $\begin{array}{l}\text { Valorização } \mathrm{da} \\
\text { competência } \\
\text { profissional }\end{array}$ & $\begin{array}{l}\text { Competência partilhada } \mathrm{e} \\
\text { mutuamente reconhecida. }\end{array}$ & $\begin{array}{l}\text { Avaliador certificado pelo } \\
\text { estado/distrito/escola. }\end{array}$ \\
\hline $\begin{array}{l}\text { Relação } \\
\text { professor- } \\
\text { supervisor }\end{array}$ & $\begin{array}{l}\text { Colegial, de reciprocidade } \\
\text { (de respeito e confiança, de } \\
\text { partilha de objetivos, de } \\
\text { experiencia e liderança). }\end{array}$ & $\begin{array}{l}\text { Hierarquizada, com alguma } \\
\text { distância de modo a tornar a } \\
\text { avaliação o mais justa e } \\
\text { neutra possível. }\end{array}$ \\
\hline $\begin{array}{l}\text { Perspetiva do } \\
\text { professor sobre o } \\
\text { processo }\end{array}$ & $\begin{array}{l}\text { Oportunidade para correr } \\
\text { riscos e experimentar. }\end{array}$ & $\begin{array}{l}\text { Desempenho máximo para } \\
\text { mostrar ao avaliador. }\end{array}$ \\
\hline
\end{tabular}

Fonte: Moreira (2009, citado por Marchão, 2011, p.3).

Atendendo ao quadro anterior, constatamos, mais uma vez, que a supervisão tem o seu enfoque no desenvolvimento profissional do professor e a avaliação tem como finalidade a formulação de valores sobre a competência, certificando-a e promovendo a progressão na carreira.

Considera-se que, num processo de supervisão-avaliação, é necessário existir, não apenas a corresponsabilização dos seus intervenientes no sistema de avaliação, mas também um diálogo permanente, numa perspetiva reflexiva que permita a "evolução do professor avaliado, a melhoria e a mudança de práticas, a qualidade e eficácia do contexto de 
ensino-aprendizagem, o desenvolvimento profissional e o estabelecimento de um ciclo reflexivo de supervisão que seja dinâmico e colaborativo" (Marchão, 2011, p. 4).

A ADD tornou-se, pois, um instrumento necessário na procura de melhores resultados para a escola. No entanto, temos verificado que a implementação do processo nem sempre tem sido "pacífica" e "consensual" e em determinados contextos educativos têm-se vivido "tempos difíceis", pois "um clima de mudança legislada e não de mudança negociada" (Day, 1993, p.97) gerou, em muitos casos, sentimentos de desconfiança, ceticismo e rejeição.

\subsection{Observação de aulas em contexto supervisivo}

Consideramos que no sentido de atingir a melhoria da qualidade da escola é fundamental desencadear, no seu interior, mecanismos que propiciem o desenvolvimento profissional do professor, enquanto agente de mudança desse contexto educativo.

Nesta perspetiva, a supervisão pedagógica adquire um papel particularmente relevante, no sentido de ajudar o docente no aperfeiçoamento das suas práticas, valorizando a reflexão sobre a ação e dando ênfase ao caráter formativo da avaliação docente. É neste processo de supervisão pedagógica e de ADD que surge a observação de aulas como mais uma ferramenta muito significativa ao serviço da melhoria da qualidade do ensino e da mudança na escola.

A observação deverá ser desenvolvida segundo um modelo de supervisão clínica uma vez que este é reconhecido como uma estratégia de supervisão com grandes potencialidades formativas e que favorece o desenvolvimento profissional e organizacional. A supervisão clínica é um processo de observação-reflexão-ação sobre a prática, centrada na resolução de problemas, o que implica uma colaboração estreita entre observador-observado (Alarcão \& Tavares, 2003).

Assim, a observação de aulas em contexto de ADD deverá ser implementada segundo um modelo reflexivo de avaliação de docentes e enquadrar-se num projeto de avaliação global da escola, que vise o desenvolvimento pessoal e profissional dos docentes, a melhoria do serviço educativo prestado e o reforço do trabalho colaborativo, com vista ao sucesso educativo dos alunos (Reis \& Alves, 2009).

Segundo Reis (2011), a observação desempenha um papel determinante na melhoria da qualidade do ensino e da aprendizagem, constituindo-se uma fonte de inspiração e de motivação e um forte catalisador de mudança na escola. A observação de aulas surge como um processo essencialmente formativo/colaborativo e contextualizado às necessidades do seu público-alvo - professores e alunos. 
Apresentam-se, no quadro VIII, algumas das finalidades da observação de aulas propostas por Reis (2011).

\section{Quadro VIII}

Algumas finalidades da observação de aulas

- Diagnosticar os aspetos/as dimensões do conhecimento e da prática profissional a trabalhar/melhorar;

- Adequar o processo de supervisão às caraterísticas e necessidades específicas de cada professor;

- Estabelecer as bases para uma tomada de decisão fundamentada sobre o processo de ensino e de aprendizagem;

- Avaliar a adequação das decisões curriculares efetuadas pelos professores e, eventualmente, suscitar abordagens ou percursos alternativos;

- Proporcionar o contato e a reflexão sobre as potencialidades e as limitações de diferentes abordagens, estratégias, metodologias e atividades;

- Desenvolver diferentes dimensões do conhecimento profissional dos professores.

Fonte: Reis (2011, p. 12).

Por último, e referenciando novamente Reis (2011), a observação de aulas deverá ser um processo com as características apresentadas no Quadro IX.

\section{Quadro IX}

Características do processo de observação de aulas

- de interação profissional e essencialmente formativo;

- que visa o desenvolvimento individual e coletivo dos professores;

- que potencializa a melhoria da qualidade de ensino e das aprendizagens;

- colaborativo e diferenciado (de acordo com as necessidades do professor);

- que promove a criação de comunidades de aprendizagem dentro da escola;

- continuado e contextualizado de desenvolvimento pessoal e organizacional;

- colaborativo entre supervisor-professor (que promova o desenvolvimento pessoal e profissional de ambos).

Fonte: adaptado de Reis (2011, pp.13-19).

Segundo vários autores, destacando Alarcão e Tavares (2010), Reis (2011) e Vieira e Moreira (2011), o ciclo de observações é constituído por três etapas que se apresentam de forma resumida, no quadro $\mathrm{X}$. 


\section{Quadro X}

Etapas do ciclo de observação de aulas

\begin{tabular}{|c|c|}
\hline Etapas & Princípios orientadores \\
\hline Pré-observação & $\begin{array}{l}\text { - Negociação das regras para a observação; } \\
\text { - Selecionar/adaptar instrumentos de observação (global ou } \\
\text { focalizada); } \\
\text { - Análise e discussão do plano de aula (com } \\
\text { caracterização/especificidades da turma); } \\
\text { Motivar o professor para a observação (postura } \\
\text { proativa/reflexiva). }\end{array}$ \\
\hline Observação & $\begin{array}{l}\text { - Recolha de informação de acordo com os focos específicos a } \\
\text { observar (definidos com o professor); } \\
\text { - Seleção das metodologias a utilizar (registos } \\
\text { descritivos/interpretativos); } \\
\text { - Seleção/conceção dos instrumentos de recolha de dados a } \\
\text { utilizar (grelhas de observação, listas de verificação, escalas de } \\
\text { classificação, mapas de registos). }\end{array}$ \\
\hline Pós-observação & $\begin{array}{l}\text { - Analisar os dados recolhidos e registados durante a observação; } \\
\text { - Refletir sobre o significado dos dados recolhidos; } \\
\text { - } \text { Fornecer feedback construtivo que vise o desenvolvimento } \\
\text { pessoal e profissional do professor; } \\
\text { - } \\
\text { - } \\
\text { Nefinir prioridades para as próximas observações; } \\
\text { (construção de sentidos). }\end{array}$ \\
\hline
\end{tabular}

Fonte: adaptado de Alarcão e Tavares (2010, pp.81-98).

Consideramos que o processo de observação de aulas só terá um impacto positivo e renovador no processo de crescimento pessoal e organizacional, se todos os atores educativos e lideranças em geral lhe reconhecerem validade e o seu carácter formativo, contextualizando-o às necessidades e especificidades de cada organização educativa - ser parte integrante das suas metodologias de supervisão organizacional.

Segundo Reis (2011), “a observação de aulas deverá sempre integrarse num processo continuado e contextualizado de desenvolvimento pessoal e organizacional, orientado por ideias claras e explícitas sobre o ensino e a aprendizagem" (p.17).

\subsection{Avaliador como supervisor pedagógico}

De acordo com Alarcão e Roldão (2010), a supervisão deve desencadear ambientes que promovam a construção e o desenvolvimento profissional e que visem, simultaneamente, o desenvolvimento da autonomia profissional dos professores. Assim, a prática de supervisão deve focalizar-se na sua vertente fundamentalmente formativa e de acompanhamento. Nesse sentido, a formação/caraterísticas do supervisor 
são estruturantes e determinantes para o sucesso de todo o processo de avaliação-supervisão.

Para Mosher e Purpel (1972, citados por Alarcão \& Tavares, 2010, p.73), existem seis áreas de caraterísticas que o supervisor deve apresentar, as quais são explicitadas no quadro XI.

\section{Quadro XI}

Caraterísticas do supervisor

- sensibilidade para se aperceber dos problemas e das suas causas;

- capacidade para analisar, dissecar e conceptualizar os problemas e hierarquizar as causas que lhes deram origem;

- capacidade para estabelecer uma comunicação eficaz a fim de perceber as opiniões e os sentimentos dos professores e exprimir as suas próprias opiniões e sentimentos;

- competência em desenvolvimento curricular e em teoria e prática de ensino;

- skills de relacionamento interpessoal;

- responsabilidade social assente em noções bem claras sobre os fins da educacão

Fonte: Alarcão e Tavares (2010, p.73).

Segundo Reis (2011), o supervisor deverá ser uma pessoa com reconhecida credibilidade a nível do "saber" e do "ser" e nesse sentido deve possuir competências significativas no âmbito da vertente profissional e da vertente pessoal. "As competências de relação interpessoal e de comunicação são decisivas no estabelecimento de uma relação de supervisão centrada na colaboração, no apoio e no aconselhamento tendo em vista o desenvolvimento de práticas lectivas adequadas" (p.17).

Teixeira e Ludovico (2007) referem que o ato supervisivo deverá estar sempre associado ao "saber olhar" do supervisor, o qual deverá manifestar/desenvolver uma atitude supervisiva abrangente, contextualizada, interpretativa e prospetiva.

Um bom supervisor lança o seu olhar entre o passado e o futuro, jogando-o no presente; dirige-o para os professores, mas relança-o para os alunos destes; focalizao na sala de aula, mas abre-o para outros contextos que com este microcosmos estabelece relações ecológicas interactivas; preocupa-se com o desenvolvimento individual dos professores, mas considera o papel que, no seu conjunto, desenvolve na educação e socialização das crianças e dos jovens (p.64). 
Neste sentido, consideramos que ao avaliador, como supervisor pedagógico, caberá a função de favorecer a maximização e a otimização das capacidades pessoais e profissionais dos avaliados, através da monitorização, da observação e da avaliação da sua ação em contexto educativo, nomeadamente, em contexto de sala de aula. A observação de aulas apresenta-se como um processo formativo e colaborativo entre professor-avaliador, onde "ambos devem desempenhar papéis importantes - antes, durante e após a observação - de forma a assegurar benefícios mútuos no desenvolvimento pessoal e profissional" (Reis, 2011, p.19).

Esta visão do supervisor como supervisor e avaliador é também contemplada no Decreto Regulamentar n..$^{\circ}$ 2/2010, de 23 de junho, através do qual se pode constatar que é ao avaliador que cabe a função de supervisão de toda a atividade docente, nomeadamente a responsabilidade última sobre o processo de avaliação de docentes.

Segundo Wiles e Bondi (2000, citados por Graça et al., 2011), para o exercício das funções supervisivas é necessário que o supervisor tenha conhecimentos nessa área de especialidade, bem como possua competências que se relacionam com a tomada de decisões e de gestão, o planeamento e a monitorização das atividades, as competências de investigação, realçando também as competências de formação pessoal, bem como a capacidade para a discussão e aconselhamento resultantes de todo o processo supervisivo.

De acordo com Reis (2011), o supervisor desempenha um papel de modelo e, consequentemente, deverá possuir competências ao nível da vertente pessoal (relação interpessoal e de comunicação) e ao nível da vertente profissional (forte credibilidade como profissional e capacidade de ouvir, de encorajar, de organizar, de acompanhar todo o processo supervisivo).

Em todo o processo supervisivo e também em qualquer modelo de ADD deverá existir uma interajuda, uma "cumplicidade pedagógica", um trabalho permanente de partilha, de saberes e de pontos de vista entre os seus intervenientes: supervisor/avaliador e professor observado/avaliado.

Assim, o professor avaliado deve interagir com o supervisor no sentido de proporcionar evidências sobre o seu desempenho (mostrar evidências pertinentes e relevantes para a sua avaliação) e proceder à sua autoavaliação numa lógica de continuidade e de melhoria progressiva do seu desempenho.

Nesse sentido, o professor avaliado deve observar e analisar o seu desempenho, numa perspetiva de professor reflexivo que constrói os significados da sua prática, identificando os seus pontos fortes, para os poder partilhar, 
e reconhecendo os seus pontos fracos, para procurar estratégias de superação e solução, entre as quais a formação que conduza ao seu desenvolvimento profissional (Graça et al., 2011, p.58).

\subsection{Avaliação e supervisão: tensões e desafios}

Considera-se que a avaliação e a supervisão deverão ser tarefas indissociáveis e implementadas de forma articulada no processo de regulação e de crescimento da organização escolar.

Defendemos que a avaliação faz parte de qualquer programa de formação ou desenvolvimento, enquanto estratégia de análise, de acompanhamento, de reflexão e de melhoria. Nesse sentido, deverá ser concebida como um instrumento a favor dos professores, da sua atuação e do seu crescimento profissional.

No entanto, a ADD tem estado na ribalta em termos de análise e de discussão entre a tutela e a classe docente, nem sempre pelos melhores motivos. Então, uma pergunta se coloca: de que forma se pode incorporar e articular, num mesmo modelo avaliativo, objetivos de melhoria das escolas e das aprendizagens e finalidades de avaliação sumativa e estandardizada? Consideramos que, no modelo em vigor, muito dificilmente...

O atual processo de ADD é um processo redutor, que não promove o desenvolvimento profissional dos professores e dos alunos. Nesse sentido, não dá resposta aos objetivos educativos, formativos e supervisivos que deveriam estar subjacentes a qualquer processo de supervisão e de avaliação, pois "a associação entre a supervisão e a função certificadora da avaliação do desempenho docente acarreta alguma suspeita sobre a primeira", remetendo-a para uma função "administrativa de controlo em que a eficiência e produtividade são a palavra de ordem" (Formosinho \& Machado, 2010, pp.108-109).

Muitos autores (Alarcão, 2001; Alarcão \& Roldão, 2010; Alarcão \& Tavares, 2010; Reis 2011; Vieira \& Moreira, 2011) defendem um modelo de avaliação de desempenho onde os professores sejam parte integrante e emancipatória de todo o processo de crescimento e de mudança da organização escolar, contribuindo, com a sua ação, para a construção de comunidades de desenvolvimento profissional. Nesse modelo, o grande objetivo da supervisão e da ADD é o desenvolvimento profissional dos professores, a sua valorização e o envolvimento nas tarefas comuns, na análise e na reflexão partilhada dos problemas e da sua superação, recorrendo, sempre que possível, a processos de investigação-ação.

Segundo Ketele (2010, citada por Vieira \& Moreira, 2011), o que a avaliação pressupõe, de acordo com uma postura sistémica em todo o processo avaliativo, não é emitir um "juízo" sobre a pessoa do professor, 
os seus comportamentos e as suas práticas, mas sim, sobre o efeito das suas práticas.

Para que tal seja possível, é necessário que exista um diálogo crítico entre todos os atores educativos e que a avaliação seja concebida como um exercício colaborativo de supervisão focalizado “(...) nas justificações e consequências da ação profissional a diversos níveis, nos seus eventuais dilemas e contradições, em busca de caminhos alternativos para professores e alunos" (p.22). Em contexto supervisivo, a avaliação surge como um processo formativo e um instrumento a favor do professor e da sua atuação profissional, conforme evidencia o quadro XII.

\section{Quadro XII}

Agentes, objetivos e quadro de referência da avaliação na supervisão

\begin{tabular}{|c|c|c|c|}
\hline Agentes & \multicolumn{2}{|c|}{ Objetivos } & $\begin{array}{l}\text { Quadro de referência } \\
\text { (ético e conceptual) }\end{array}$ \\
\hline $\begin{array}{l}\mathrm{O}(\mathrm{s}) \text { supervisor(es) } \\
\mathrm{O}(\mathrm{s}) \text { professor(es) } \\
\mathrm{O}(\mathrm{s}) \text { aluno(s) } \\
\text { Outros elementos da } \\
\text { comunidade educativa } \\
\text { (encarregados de } \\
\text { educação, colegas, ...) }\end{array}$ & $\begin{array}{l}\text { Teorias } \\
\text { Práticas } \\
\text { Contextos }\end{array}$ & $\begin{array}{l}\text { Pedagógicos } \\
\text { Supervisivos }\end{array}$ & $\begin{array}{l}\text { Condições de uma formação } \\
\text { reflexiva } \\
\text { Condição de uma pedagogia } \\
\text { para a autonomia } \\
\text { Princípios reguladores das } \\
\text { práticas supervisivas } \\
\text { (decorrentes dessas condições) }\end{array}$ \\
\hline
\end{tabular}

Fonte: Vieira e Moreira (2011, p.22).

Vários autores (Alarcão \& Roldão, 2010; Alarcão \& Tavares, 2010; Reis 2011; Vieira \& Moreira, 2011) consideram que os dilemas e tensões inerentes à atividade supervisiva e avaliativa de professores resultam de diversos fatores, nomeadamente: assimetria profissional, experiencial e estatutária dos professores avaliadores e avaliados; rotinas enraizadas na escola, que dificultam a predisposição para a mudança; pouca tradição das práticas supervisivas; conflito entre apoio e supervisão/credibilidade e preparação técnica dos supervisores; transparência e consenso relativamente à validade e à fiabilidade de todo o processo supervisivoavaliativo, entre outras.

Assim, avaliadores e avaliados devem considerar-se como agentes de mudança num processo sistémico e como líderes transformadores da aprendizagem dos alunos e do trabalho nas escolas. O grande desafio prende-se com o desenvolvimento no interior das escolas de comunidades de aprendizagem dialógicas, sugerindo-se a implementação de um estilo supervisivo não diretivo no acompanhamento de planos autodirigidos de desenvolvimento profissional (Glickman, 2002, citado por Vieira \& Moreira, 2011).

Todo o processo avaliativo deve promover a mudança da atuação dos professores, através do "recurso a estratégias auto-supervisivas 
potencialmente transformadoras da ação e das situações de trabalho" (Vieira \& Moreira, 2011, p.25).

Consideramos que o grande desafio da atualidade é criar, no interior das escolas, um clima de confiança, de diálogo e de corresponsabilidade entre todos os seus agentes educativos, que resulte na implementação de um processo de ADD partilhado, reflexivo e essencialmente formativo.

Defendemos que cada escola é uma escola, logo cada uma, na sua singularidade, deve olhar para o seu interior de forma responsável e empenhada de modo a ajustar o seu trabalho diário às suas necessidades e especificidades. Nesse sentido, é necessário criar no seu interior uma cultura de cooperação, de partilha, de interajuda, de formação, de atualização, entre outras, que vise a melhoria permanente da organização educativa e o crescimento profissional de todos os seus atores educativos.

Defendemos, por último, que estes objetivos só poderão ser concretizados com êxito se cada organização inscrever a supervisão e a ADD como práticas diárias que permitem conhecer, compreender, analisar, melhorar as práticas educativas e dignificar o trabalho de todos os que diariamente trabalham e "constituem" a escola pública.

$\mathrm{Na}$ educação nada é simples e linear... Tudo exige "o olhar supervisivo da interrogação da realidade para a sua compreensão e transformação" (Vieira \& Moreira, 2011, p.62).

\section{CONCLUSÃO}

Sabemos que a escola tem a grande tarefa de estar atenta, de "saber observar" e de "saber diagnosticar" as constantes mudanças e alterações que vão ocorrendo na sociedade e no mundo cada vez mais competitivo e global/globalizante.

Nesse sentido, caberá à organização escola criar, no seu interior, dinâmicas e modus operantes que deem resposta a essas necessidades...

É neste cenário educativo que surge a supervisão pedagógica com a função de apoio, de acompanhamento, de suporte à prática, de contextualização, de reflexão e de melhoria de toda a atividade docente, contribuindo para o crescimento profissional de todos os atores educativos.

Esta ideia é corroborada por Machado, Costa e Alves (2013), ao defenderem que a escola deve organizar-se segundo uma perspetiva de aprendizagem colaborativa, reflexiva e aprendente, uma vez que:

na construção de um ensino e de uma escola de qualidade, torna-se determinante a promoção de uma cultura de trabalho reflexiva, dialógica e de partilha, promovida por uma supervisão colaborativa, propiciadora de ambientes 
de mais autonomia por parte dos docentes e, consequentemente, das instituições escolares (p.115).

$\mathrm{Na}$ perspetiva de melhoria do ensino que a escola presta e do desenvolvimento profissional dos seus professores, surge a ADD que deverá promover a realização profissional, a autonomia, a autoavaliação e a colaboração entre todos os atores educativos (avaliadores/supervisores e avaliado/professor), promovendo, desta forma, uma cultura avaliativa credível, justa, essencialmente formativa e potencializadora da mudança e da melhoria das práticas pedagógicas implementadas pelos seus profissionais.

Todo este processo de supervisão-avaliação requer supervisores, professores e avaliadores corresponsabilizados e empenhados em todo o seu processo de atualização, de formação e de melhoria ao longo da sua vida profissional. Assim, a formação contínua e contextualizada é enfatizada como um pilar determinante para o crescimento pessoal e profissional de todos os interlocutores que constituem a escola dos nossos dias.

A supervisão pedagógica e a ADD podem e devem criar sinergias e complementaridade no sentido de otimizar o serviço educativo que a escola presta aos seus alunos, bem como instituir-se como um mecanismo de crescimento profissional e organizacional, tal como advogam os autores estudados.

No entanto, nos modelos de ADD implementados até ao momento, não são visíveis os seus efeitos no tocante à melhoria do desempenho profissional dos professores, do ensino e, portanto, das aprendizagens efetuadas pelos alunos.

A ADD tem surgido essencialmente como um processo burocrático, longínquo de um modelo de supervisão pedagógica-avaliação formativa e sem pressupor grande afinidade/articulação entre a ADD e as melhorias de desempenho dos seus profissionais.

De acordo com Lima (2010), vivemos sobre o domínio do "Estadoavaliador" que "vem transformando a avaliação num instrumento de governação e numa técnica de gestão" (p.5), o que é evidenciado no atual modelo de ADD.

A este propósito, Vieira e Moreira (2011) referem que:

(...) a avaliação e a supervisão deverão construir caminhos de libertação de uma lógica de controlo e sujeição rumo a uma lógica de transformação e emancipação, sabendo-se, contudo, que as duas lógicas coexistem de forma conflitual, gerando dilemas e paradoxos com os quais é necessário aprender a lidar (p.9). 
Consideramos que o grande desafio da escola atual será criar no seu interior uma "cultura de avaliação-supervisão", onde a ADD surja como uma "necessidade" e uma "exigência" dos seus profissionais e da organização educativa.

De acordo com este paradigma, o processo de ADD será desenvolvido de forma contínua, numa vertente de acompanhamento do trabalho dos professores, que permita às instituições atingir, de modo mais eficaz, as metas e os objetivos traçados para a própria organização e a sua comunidade discente, bem como promover o desenvolvimento profissional dos seus professores.

Fica o desafio e a esperança de que a escola consiga potencializar, no seu interior, verdadeiras respostas formativas, onde a supervisão pedagógica e a ADD sejam uma realidade ao serviço da melhoria e crescimento da escola pública.

\section{FONTES E BIBLIOGRAFIA}

Alaiz, V., Gois, E., \& Gonçalves, C. (2003). Auto-avaliação de EscolasPensar e praticar. Porto: Edições ASA.

Alarcão, I. (2001). Escola reflexiva e Supervisão-uma escola em desenvolvimento e aprendizagem. Porto: Porto Editora.

Alarcão, I., \& Tavares, J. (2003). Supervisão da prática pedagógica uma perspectiva de desenvolvimento e aprendizagem ( $2^{\mathrm{a}}$ edição). Coimbra: Livraria Almedina.

Alarcão, I., \& Roldão, M. (2010). Supervisão. Um contexto de desenvolvimento profissional dos professores ( $2^{\mathrm{a}}$ edição). Mangualde: Edições Pedago.

Alarcão, I., \& Tavares, J. (1987). Supervisão da prática - uma perspectiva de desenvolvimento e aprendizagem. Coimbra: Livraria Almedina.

Alarcão, I., \& Tavares, J. (2010). Supervisão da prática pedagógica uma perspectiva de desenvolvimento e aprendizagem (2 ${ }^{\mathrm{a}}$ edição revista e desenvolvida). Coimbra: Livraria Almedina.

Baptista, J. A. (2013). Avaliação do desempenho docente: o que mexe com os professores. Revista de Gestão e Desenvolvimento, 21, 261344.

Cruz, I. M. (2009). Observação de Aulas: Estratégias de Desenvolvimento Profissional. Revista ELO 16, pp.137-145.

Day, C. (1993). Avaliação do desenvolvimento profissional de professores. In A. Estrela \& A. Nóvoa (orgs.), Avaliação em educação: Novas perspectivas (pp. 95-114). Porto: Porto Editora.

Decreto Regulamentar n. ${ }^{\circ}$ 2/10, de 23 de junho. 
Formosinho, J., \& Machado, J. (2010). Desempenho, mérito e desenvolvimento - para uma avaliação mais profissional dos professores. In J. Formosinho, J. Machado \& J. Oliveira-Formosinho (autores). Formação desempenho e avaliação de professores (pp.97118). Mangualde: Edições Pedago.

Garmston, R., Lipton, L., \& Kaiser, K., (2002). A Psicologia da Supervisão. In J. Oliveira-Formosinho (org.), A Supervisão na Formação de Professores II. Da organização à pessoa (pp.18-132). Porto: Porto Editora.

Guerra, M.A.S. (2003). Uma seta no alvo: A Avaliação como Aprendizagem. Porto: Edições ASA.

Gonçalves, J. A. (2009). Desenvolvimento profissional e carreira docente: fases da carreira, currículo e supervisão. Sísifo. Revista de Ciência da Educação, 8, 23-36.

Graça, A., Duarte, A. P., Lagartixa, C., Tching, D., Tomás, I., Almeida, J., Santos, R., Neves, P., \& Diogo, M. J. (2011). Avaliação do Desempenho Docente. Um guia para a ação. Lisboa: Lisboa Editora, S.A.

Holly, M. L. (2007). Investigando a vida profissional de professores: diários biográficos. In A. Nóvoa (org.), Vidas de professores (pp.79110). Porto: Porto Editora.

Lima, J. A. (2010). Avaliação, competitividade e hiperburocracia. Conferência de abertura do $22^{\circ}$ Colóquio internacional da ADMEE. Disponível

em:

http://webs.iep.uminho.pt/admee/ficheiros/resumo_ADMEE.

Consultado em 23 de agosto de 2013.

Machado, E. A., Costa, N., \& Alves, M. P. (2013). Avaliação de Desempenho Docente. Compreender a complexidade, sustentar a decisão. Santo Tirso: De Facto Editores.

Marchão, A. J. (2011). Desenvolvimento Profissional dos Educadores e dos Professores - É possível conciliar a supervisão e a avaliação de desempenho? PROFFORMA n. ${ }^{\circ} 03$ - Junho.

Oliveira-Formosinho, J. (2002a). Introdução. In J. Oliveira-Formosinho (org.), A Supervisão na Formação de Professores II. Da organização à pessoa (pp.9-15). Porto: Porto Editora.

Oliveira-Formosinho, J. (2002b). Em direcção a um modelo ecológico de supervisão de professores. Uma investigação na formação de educadores de infância. In J. Oliveira-Formosinho (org.), A Supervisão na Formação de Professores I. Da sala à escola (pp.94120). Porto: Porto Editora.

Reis, P. M. J., \& Alves, M. P. C. (2009). Observação de Aulas em Contexto de ADD: um projeto de escola à procura dos referentes. 
Atas do $\mathrm{X}$ Congresso Internacional Galego-português de Psicopedagogia. Braga: Universidade do Minho, pp. 3910 - 3923.

Reis, P. (2011). Observação de aulas e avaliação do desempenho docente. Ministério da Educação - Conselho Cientifico para a Avaliação de Professores. Caderno do CCAP - 2 .

Teixeira, O., \& Ludovico, A. (2007). Educação Pré-Escolar: Currículo e Supervisão. Penafiel: Editorial Novembro.

Tracy, S. J. (2002). Modelos e abordagens. In J. Oliveira-Formosinho (org.), A Supervisão na Formação de Professores I. Da sala à escola (pp.19-92). Porto: Porto Editora.

Vieira, F., \& Moreira, M. A. (2011). Supervisão e avaliação do desempenho docente. Para uma abordagem de orientação transformadora. Cadernos do Conselho Científico para a Avaliação de Professores - 1. Lisboa: Ministério da Educação. 